\title{
Manipulation of Fertility in Crossbred Dairy Cattle Using Controlled Internal Drug Release Device Combined With Prostaglandin and Equine Chorionic Gonadotrophin
}

\author{
Alemselam Birhanu Mekonnin ${ }^{1,}$ *, A. Forbes Howie ${ }^{1}$, Christopher R. Harlow ${ }^{1}$, Goitom Gidey ${ }^{2}$, \\ Desalew Tadesse Tegegne ${ }^{2}$, Gidena Desta ${ }^{2}$, Tadesse Gugsa ${ }^{3}$, Berihu Gebrekidan ${ }^{2}$, \\ Gebregiorgis Ashebir ${ }^{2}$, Simon C. Riley ${ }^{1}$ \\ ${ }^{1}$ MRC Centre for Reproductive Health, The Queen's Medical Research Institute College of Medicine and Veterinary Medicine, University of \\ Edinburgh, Edinburgh, United Kingdom \\ ${ }^{2}$ College of Veterinary Medicine, Mekelle University, Mekelle, Ethiopia \\ ${ }^{3}$ Tigray Regional State Agriculture Bureau, Tigray, Mekelle, Ethiopia
}

Email address:

a.b.mekonnin@sms.ed.ac.uk (A. B. Mekonnin)

${ }^{*}$ Corresponding author

\section{To cite this article:}

Alemselam Birhanu Mekonnin, A. Forbes Howie, Christopher R. Harlow, Goitom Gidey, Desalew Tadesse Tegegne, Gidena Desta, Tadesse Gugsa, Berihu Gebrekidan, Gebregiorgis Ashebir, Simon C. Riley. Manipulation of Fertility in Crossbred Dairy Cattle Using Controlled Internal Drug Release Device Combined With Prostaglandin and Equine Chorionic Gonadotrophin. Animal and Veterinary Sciences. Vol. 4, No. 3, 2016, pp. 39-46. doi: 10.11648/j.avs.20160403.12

Received: December 13, 2015; Accepted: April 27, 2016; Published: May 23, 2016

\begin{abstract}
Simplifying and improving our understanding of the protocols for inducing or synchronizing estrus is important for improving management of dairy cattle. This study evaluated the estrus response and conception rate of crossbred (Holstein Friesian X Zebu) dairy cows $(n=75)$ and heifers $(n=47)$ assigned to a 10-day controlled internal drug release (CIDR) device prostaglandin F2-alpha (PGF2 $\alpha$ ) - equine chorionic gonadotrophin (eCG) based estrus synchronization protocol. Animals were assigned to three groups (a) anestrus ( $\mathrm{n}=62)$, (b) repeat-breeders $(\mathrm{n}=11)$ and (c) silent estrus ( $\mathrm{n}=46$ ), according to their reproductive history, per rectal palpation, and progesterone concentrations determined by On-Farm enzyme-linked immunosorbent assays (ELISA) in milk (lactating cows) or serum (dry cows and heifers). For each animal, a CIDR device (containing $1.38 \mathrm{~g}$ progesterone) was inserted into the vagina and allowed to remain in-situ for 10 days. On Day 8 after device insertion, a dose of 500 $\mathrm{g}$ of PGF2 $\alpha$ was administered intramuscularly (IM). On Day 10 (device removal), 500 IU of eCG was given IM. Animals were inseminated or mated 48 and $72 \mathrm{hrs}$ post device removal. Pregnancy was assessed 20-24 days post insemination by measurement of progesterone in milk/serum and pregnancy was confirmed by per rectal palpation and/or ultrasonography 44-90 days post insemination. Overall estrus response and conception rates were $97.5 \%$ and $78.3 \%$, respectively, with no significant differences in parity, pre-treatment reproductive status and farming system (smallholder vs organized commercial farms). Conception rate after induced/synchronized estrus was $82.9 \%$ and $72.1 \%$ in cows and heifers, respectively, with an overall calving rate of $94.4 \%$. In conclusion, the present study has shown high estrus response and conception rate in crossbred dairy cattle using this CIDR - PGF $2 \alpha$ - eCG based estrus synchronization protocol. Application of this protocol is highly recommended to enhance fertility of dairy cattle in the study area, and this could readily be applied to other regions.
\end{abstract}

Keywords: Cattle, CIDR, eCG, Estrus, Fertility, PGF2 $\alpha$, Synchronization

\section{Introduction}

Ethiopia possesses the tenth largest cattle population in the world, and the largest in Africa. Despite this, productivity and reproductive performance of its indigenous and crossbred (Holstein Friesian X Zebu) cattle herd is poor [1, 2]. Efficient reproduction underpins a profitable dairy industry [3] and producing one calf per year per cow is an 
important step in achieving this. Cows must get pregnant and maintain the pregnancy with parturition 270 days post service/AI, and wait for a period of 40-50 days (voluntary waiting period) to be successfully inseminated again [4]. This results in one calf per year per cow with regular availability and increased milk production in the dairy farm, together with the provision of replacement heifers. However, there are a number of factors affecting reproduction in dairy cattle, particularly in the tropics, where both reproductive performance as well as milk production of local (Zebu) and crossbred, including Holstein Friesian, is regarded as poor. The main reasons are poor nutritional status, estrus detection, AI technique or breeding management and postpartum uterine disease and calf suckling [5]. Anestrus and repeatbreeding are the major problems affecting the reproductive performance of crossbred dairy cattle in Ethiopia [6]. Both anestrus and repeat-breeding lead to a longer calving interval. In smallholder farms, most cows including crossbreeds, fail to calve every 12 to 13 months after the first calving $[6,7]$. Puberty in crossbred (Zebu x Holstein-Friesian/HF) heifers is usually 24 months [8], and heifers are also reported to be older at first calving $[1,2,6]$.

A successful breeding program must incorporate efficient and accurate detection of estrus, proper semen handling techniques, and timely AI [9]. Failure of proper estrus detection is the most common problem in dairy cattle breeding programs $[9,10]$ resulting in loss of lifetime milk yield, a decrease in number of calves born per lifetime, excessive days open, and an increase in reproductive culling [9]. As the accuracy and efficiency of estrus detection declines, it is important to incorporate estrus synchronization/induction and timed AI into the breeding management program [11]. Estrus synchronization can avoid or reduce the need for estrus detection, and increases the fertility and productivity of cattle [12]. Furthermore, estrus synchronization facilitates planning of AI, shortens first day service in postpartum cows, reduces the calving interval and helps to maintain uniform calf crops and replacement heifers $[12,13]$.

Current world-wide research is focused on the development of methods that effectively synchronize estrus by decreasing the period of time over which estrus is detected, hence facilitating the use of fixed time AI [14]. Progesterone based estrus synchronization protocols are more advantageous than others. A controlled internal drug release (CIDR) based estrus synchronization protocols have been widely studied $[15,16]$, and are more preferable than using prostaglandin (PGF2 $\alpha$ ) alone, due to ineffectiveness of PGF $2 \alpha$ to induce cyclicity/ estrus in animals that do not have a corpus luteum (CL), nor does it exert an effect on follicular wave [17]. Most successful estrus synchronization protocols have been developed in Bos taurus cattle, however in Bos indicus breeds, utilization of same synchronization protocols results in low to unacceptably low pregnancy rates $[15,18]$.

It has been demonstrated that CIDR can be maintained in the vagina for a longer period of 14 days [19], however, intravaginal devices maintained over 12 days reduces fertility by causing aged follicles [20, 21, 22]. Promising developments have been shown by reducing the time of keeping CIDR devices in the vagina to 4 [23] or 5 days [15, 24], although estrus response and conception rates are not consistent even after the use of the standard 7-day CIDR regime $[3,25,26]$ which could be due to environmental, management, breed and other factors. Yet, a recent report showed a similar pregnancy success when CIDR was maintained for 5 days, 6 days and 14 days in heifers [27]. Moreover, another recent study that compared between 7 and 9 days CIDR inserts on estrus response and fertility in dairy cattle has shown a similar effect between the two protocols [28]. Others have suggested that keeping intravaginal devices for a period of 10 to 12 days has no negative effect on fertility and recommended for use in controlled breeding programs in cattle $[20,22,25]$.

In view of the poor estrus detection and reproductive performance of crossbred dairy cattle in the Ethiopia $[1,2,6$, $29,30]$, it is necessary to establish an estrus synchronization program that can operate under any reproductive condition (anestrus and cycling) as a management tool to enhance their fertility and productivity. The objective of the present study was to evaluate the reproductive performance of crossbred dairy cattle following treatment with a 10-day CIDR in combination with PGF $2 \alpha$ and eCG.

\section{Materials and Methods}

\subsection{Study Area}

The proposal was presented to key stakeholders and livestock experts and approved by The Government of National State of Tigray Bureau of Agriculture and Rural Development, Tigray, Ethiopia. It was conducted from November 2013 to December 2014 in and around Mekelle, the largest city in northern Ethiopia, and the capital city of Tigray, which is located at $39^{\circ} 29^{\circ} \mathrm{E}$ and $13^{\circ} 30^{\prime} \mathrm{N}$ at an altitude of 2000 m.a.s.l. The climate of the study area conforms to that of Ethiopian Highlands. The mean annual rainfall is $619 \mathrm{~mm}$, and is bimodal with a short rainy season occurring from March to May and another from middle September to February. The annual minimum and maximum temperature is $11.8^{\circ} \mathrm{C}$ and $29.9^{\circ} \mathrm{C}$, respectively [31].

\subsection{Study Farms and Animals}

Crossbred dairy cattle owned by smallholder farms and organized commercial farms were included in this study. Cattle in both farm types were fed grass hay or straw, concentrate composed of wheat by products, crop residues and local beer residue (Attela). However, cows in organized commercial farms were supplemented with green fodder, such as fresh grass, alfalfa, elephant grass, lucinia and suspania, they received regular watering; and, the farms had better breeding records and housing condition. A total of 122 dairy cattle ( 75 cows with a mean age of 6.6 years old and $>60$ days postpartum and 47 heifers with a mean age of 3.1 years old) from smallholder farmers and organized 
commercial farms, with an average body condition score (BCS) of 3.1 (on a scale of 1-5) [32] were assigned in the study. Reproductive organs of the study animals were assessed for genital tract pathology using per rectal palpation, and only apparently health animals were included in the study. Study animals were assigned into three groups prior to treatment as (a) anestrus (non-cycling, $n=67$ ), (b) repeatbreeders (normally cycling and observed estrus, but never conceived despite multiple inseminations, $\mathrm{n}=11$ ), and (c) silent estrus (cycling but no visible estrus signs, $n=44$ ) according to their reproductive history, two equivalent onfarm progesterone assays, dipstick (Progesterone Rapid, Ridgeway Science Ltd, Gloucestershire, UK) in milk (cows) or Target Progesterone ELISA (Biometallics Inc, New Jersey, USA) in serum (heifers) and per rectal palpation. Progesterone assays were carried out twice at 11 days interval immediately after breeding history was recorded, which was immediately followed by per rectal examination of ovarian and uterine conditions [30].

\subsection{Study Design}

Treatment regime is schematically illustrated in Figure 1. The perineal region of each animal was thoroughly washed with water, an Eazi-Breed CIDR ${ }^{\mathrm{TM}}$ (CIDR $^{\circledR}$, Pfizer Ltd, Kent, UK) device, containing $1.38 \mathrm{~g}$ of progesterone, was inserted into the vagina and allowed to remain in-situ for 10 days. On the $8^{\text {th }}$ day after device insertion, a dose of 500 $\mu$ g PGF $2 \alpha$ (Estrumate, Schering-Plough Animal Health Corp, Summit, Germany) was administered intramuscularly (IM). On the day of device removal (Day 10), 500 IU (Equine chorionic gonadotropin (eCG) (Intervet UK Ltd, Walton, UK) was injected IM. The estrus response was compared according to parity (cows vs heifers), pre-treatment group (anestrus, repeat-breeders and silent estrus) and farming systems (smallholder vs organized commercial farms). Animals were inseminated using frozen semen or naturally mated twice at 48 and $72 \mathrm{hrs}$ post device removal. Animals were examined for presence of pregnancy 20-24 days (average of 21 days) post insemination by on-farm milk (lactating cows) progesterone test using Dipstick or on-farm serum (dry cows and heifers) progesterone test using Target progesterone kits, and pregnancy was confirmed by per rectal palpation/ ultrasonography (KX5200V, Kaixin ${ }^{\circledR}$, Xuzhou Kaixin Electronic Instrument Co., Ltd, Xuzhou, Jiangsu, China) 4490 days post insemination/mating. Conception rate was compared according to the variables above and between breeding methods (AI vs natural mating). Data were analysed using Fisher's exact test and Chi-square test using GraphPad Prism (GraphPad Software, Inc, CA, USA). Differences were considered significant when $\mathrm{p}<0.05$.

\section{Results}

The overall estrus response and conception rate in the present study was $97.5 \%$ and $78.3 \%$, respectively. There was similar estrus response between cows and heifers (Table 1). Although, the estrus response of cattle to CIDR - PGF2 $\alpha$ -
eCG treatment, based on observed estrus behaviour recorded by the farmers, was $97.5 \%$, the remaining animals $3 / 122$ $(2.5 \%)$ that did not exhibit external symptoms, were deemed fit for insemination as their cervices were open, as evidenced by the AI gun easily passing through to deposit semen in the uterine body. This brought the estrus response to $100 \%$. Subsequently, three $(2.5 \%)$ animals (two cows and one heifer did not retain their CIDR. Of 119 animals in estrus, 115 $(96.6 \%)$ were inseminated or naturally mated, however four (3.4\%) were not bred due to various reasons including animals being unable to be inseminated or mated.

The conception rate in cows and heifers was $82.9 \%$ and $72.1 \%$ respectively, which was not significantly different $(p>0.05)$ (Table 1). Similar conception rates were found between anestrus, repeat-breeders and normally cycling-but silent estrus/unobserved by the farmers (Table 2). Natural mating resulted in a higher conception rate than AI, but the difference was not significant (Table 3). The farming system did not affect estrus response or conception rate (Table 4).

Two cows and one heifer gave birth to twin calves, while the remaining deliveries were singletons. Of 90 pregnant cows/heifers $85(94.4 \%)$ successfully calved, and there was no effect of parity (Table 1), pre-treatment reproductive status (Table 2), breeding method (Table 3) or farming system (Table 4). Pregnancy loss occurred in 4/90 (4.4\%) animals: three cows $(3 / 59,5.1 \%)$ and one heifer $(1 / 31,3.2 \%)$. These losses occurred in one cow in a smallholder farm with the remaining losses of two cows and one heifer in organized commercial farms where animals were bred by AI. There was also death of a pregnant cow $(1 / 90,1.1 \%)$ in one of the organized commercial farms due to lumpy skin disease.

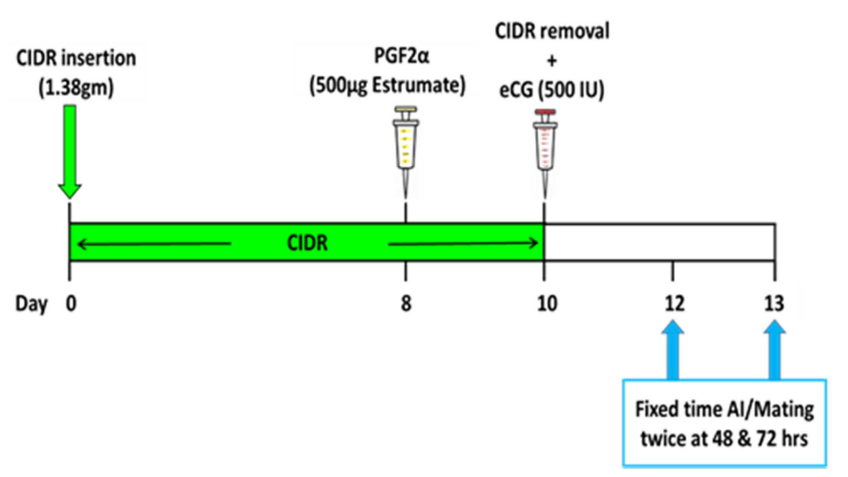

Figure 1. Schematic representation of treatment regime.

Table 1. Estrus and conception status of cows and heifers treated with CIDR - $P G F_{2 \alpha}$ - eCG combination estrus synchronization protocol.

\begin{tabular}{llll}
\hline \multirow{2}{*}{ Observations } & \multicolumn{3}{c}{ Treated animals } \\
\cline { 2 - 4 } & Total* & Cows* & Heifers* \\
\hline No. treated & $122(100)$ & $75(100)$ & $47(100)$ \\
No. in estrus & $119(97.5)$ & $73(97.3)$ & $46(97.9)$ \\
Number mated/ inseminated & $115(96.6)$ & $72(98.6)$ & $43(93.5)$ \\
$\begin{array}{l}\text { No. conceived at } \\
\text { induced/synchronized estrus }\end{array}$ & $90(78.3)$ & $59(82.9)$ & $31(72.1)$ \\
No. calved & $85(94.4)$ & $56(94.9)$ & $29(93.5)$ \\
\hline
\end{tabular}

*Values in parentheses are percentages. 
Table 2. Fertility status of cows and heifers post CIDR - PGF2 - eCG combination treatment on the basis of pre-treatment reproductive history and status.

\begin{tabular}{lllll}
\hline Observation & Total* & Anestrus* & Repeat-breeders* (Observed estrus) & Silent estrus/ unobserved estrus* \\
\hline No. of animals mated/ inseminated & $115 / 122$ & $62 / 67(92.5)$ & $11 / 11(100)$ & $42 / 44(95.4)$ \\
Conception rate (\% pregnant/ AI or mated) & $90(78.3)$ & $48(77.4)$ & $8(72.7)$ & $34(81.0)$ \\
No. calved & $85(94.4)$ & $44(91.7)$ & $7(87.5)$ & $34(100)$ \\
\hline
\end{tabular}

*Values in parentheses are percentages.

*Silent/unobserved estrus: cattle in this group were reported by the farmers as anestrus, however on-farm progesterone tests along with per rectal palpation confirmed them cycling.

Table 3. Fertility status of cows and heifers following estrus synchronization/induction on the basis of breeding methods.

\begin{tabular}{|c|c|c|c|}
\hline \multirow{2}{*}{ Observation } & \multirow{2}{*}{ Total* } & \multicolumn{2}{|c|}{ Breeding Method } \\
\hline & & AI* & Natural mating* \\
\hline No. of animals mated/inseminated & 115 & $95(100)$ & $20(100)$ \\
\hline No. conceived at induced/synchronized estrus & $90(78.3)$ & $72(75.8)$ & $18(90)$ \\
\hline No. calved & $85(94.4)$ & $68(94.4)$ & $17(94.4)$ \\
\hline
\end{tabular}

*Values in parentheses are percentages.

Table 4. Fertility status of cows and heifers treated following estrus synchronization/induction on the basis of farming system.

\begin{tabular}{llll}
\hline observations & Total & $\begin{array}{l}\text { Smallholder } \\
\text { farms }\end{array}$ & $\begin{array}{l}\text { Organized } \\
\text { commercial farms }\end{array}$ \\
\hline No. treated & 122 & 34 & 88 \\
No. inseminated & 115 & 33 & 82 \\
No. pregnant & $90(78.3)$ & $24(72.7)$ & $66(80.5)$ \\
No. calved & $85(94.4)$ & $22(91.7)$ & $63(95.4)$ \\
\hline
\end{tabular}

*Values in parentheses are percentages.

\section{Discussion}

A simple procedure that uses solely CIDR inserts without any combination treatment on the initial day was performed in this study. This is unlike previous reports $[26,33]$ that used CIDR in combination with a Co-Synch or Ovsynch protocol (gonadotrophin-releasing hormone (GnRH)- PGF2 $\alpha-G n R H$ combination protocol) whereby $\mathrm{GnRH}$ is administered simultaneously with CIDR on the initial day, which has been demonstrated to be effective. Progesterone delays the time of estrus after natural or induced luteolysis and extends the oestrous cycle by preventing the occurrence of spontaneous estrus [34]. Administration of PGF2 $\alpha$ on Day 8 of CIDR insertion was intended to cause regression of the $\mathrm{CL}$ and to bring the animals into estrus 1-3 days post treatment. The PGF $2 \alpha$ reduces the risk of continued progesterone production by a functional CL after device removal [35]. eCG has both follicle stimulating hormone (FSH) and luteinizing hormone (LH) like activity in bovine [36], but with more of FSH activity [37]. Therefore, administration of eCG on the day of device removal stimulates follicular development, final maturation of the dominant follicle, initiation of ovulation and CL formation $[36,38]$. Furthermore, in the present study three animals gave birth to twin calves, which could be due to administration of gonadotrophins, such as eCG that can cause superovulation [39].

In the present study the retention of CIDR exceeded $97 \%$ which is comparable with previous reports [25, 40], although, others reported no CIDR loss [21]. Animals which did not show external symptoms of estrus, but when inseminated had open cervices evidenced when the AI gun was easily and smoothly passed through the cervix is suggestive of silent estrus post CIDR treatment. In agreement with our finding, a previous report showed that $2 \%$ of CIDR treated heifers had a palpable CL, although they were not observed in estrus [25]. All animals which were reported by the farmers as anestrus, but confirmed cycling by the on-farm progesterone tests, showed external symptoms of estrus when subjected to the present estrus synchronization protocol, which indicates poor estrus detection. Furthermore, all anestrus (except 3 with just their cervical os opened) and repeat-breeder cattle, including those with silent/unobserved estrus showed external symptoms of estrus following estrus synchronization. CIDR treatment in anovulatory and anestrus cows/heifers re-establishes the hypothalamic responsiveness to estradiol produced from the dominant follicle. It also normalizes the duration of the luteal phase [41], and increases estradiol responsiveness in behavioural centres of the brain $[42,43]$ thereby increasing the proportion of cattle expressing behavioural estrus in conjunction with ovulation [44, 45].

The high estrus response and conception rate in the present study is possibly due to the exclusion criteria such as unacceptable BCS, assessment of pre-treatment reproductive condition of animals as unfit for estrus synchronization (having unhealthy and small sized reproductive tract and organs), and the use of double insemination or mating at 48 and 72 Hrs. Previous reports have shown that BCS and uterine infections are among the factors that reduce fertility [46]. Despite the difference in reproductive status of animals (anestrus/cycling) prior to CIDR insertion, a high estrus response was found in both cows and heifers in the present study. This is in agreement with previous studies that reported a $100 \%$ estrus response using a 7-day CIDR and eCG injection in 30 anestrus Zebu breed cows [47], a 100\% response in 73 crossbred cows with unknown ovarian cyclicity using a 7-day CIDR in combination with PGF2 $\alpha$ and GnRH [3] and a 100\% response in anestrus Sahiwal (Zebu) cows when used a 9-day CIDR in combination with eCG injection one day prior to CIDR removal and hCG at the 
time of AI [48]. Conversely, the present study improved on other studies that reported $79.5 \%$ and $87.5 \%$ estrus response using 7-day and 9-day CIDR, respectively in combination with PGF $2 \alpha$ in 128 Holstein Friesian / crossbred dairy cows [28], 86.7\% using Ovsynch + CIDR in 55 repeat-breeder Holstein Friesian cows [26], 80\% in 5 normally cycling Aceh cattle in Indonesia using CIDR-B + PGF2 $\alpha$ [16] and Bos indicus and other cattle breeds $[12,15]$.

There were similar conception rates between anestrus, repeat-breeder and silent estrus crossbred dairy cattle in this study, with a high overall conception rate $(78.3 \%)$ similar to reports in anestrus Zebu breed cows (70\%) in India [47]. The present study has shown a better conception rate than reports in crossbred cattle $(40.9 \%)$ in the tropics [3], in Holstein Friesian/crossbred cows (45.5\%) [28], in Bos indicus cattle [15] and in beef cattle in USA [12], and in beef heifers (54.5/55.5\%) using 14-day/ 5-dayCIDR protocols [49] that reported lower pregnancy rates, $54.5 \%$ and $55.5 \%$, when used long and short term CIDR protocols, respectively. Moreover, the present study has shown better conception rate in repeat breeder cows/heifers than previous reports in South Korea [26] and Japan [33]. Conversely, conception rate in the present study was lower than previous reports that used CIDR treatment in Aceh cattle (100\%) in Indonesia [16]. However, their study was only in 5 cattle; therefore, higher conception rate may reflect their small sample size. Nevertheless, conception rate can be affected by factors such as nutrition, breed, postpartum interval, and geographic location $[50,51]$.

The conception rate in cows $(82.9 \%)$ was slightly higher, but not significant, than in heifers $(72.1 \%)$ in the present study. Contrary to our findings, a previous report showed higher conception rate in heifers $(67.9 \%)$ than cows $(53.1 \%)$ [52]. The present study recorded lower pregnancy loss $(5.1 \%)$ in cows compared with previous reports where the loss in cows was $20 \%$ when PGF $2 \alpha /$ progestins was used [53]. Infectious diseases, and non-infectious factors such as poor management systems, milk yield, parity, BCS, ambient temperature [54] can cause pregnancy loss.

By way of direct comparison, the estrus response recorded in the present study was higher than our recent report that used single or double administration of PGF2 $\alpha$ with simultaneous administration of GnRH [55]. The present study had a higher $(78.3 \%)$ conception rate than our recent report in same study area when repeat-breeder crossbred dairy cattle were subjected to $20 \mu \mathrm{g}$ or $10 \mu \mathrm{g} \mathrm{GnRH}$ (Buserelin acetate) (68\%) [29]. Furthermore, the present study has shown a higher conception rate than was observed in the large scale controlled reproduction program in Tigray region that used PGF $2 \alpha(31.5 \%)$ in local/ crossbred dairy cattle [56]. This may be due to progesterone having a positive effect in inducing/ synchronizing estrus in anestrus and cycling cattle, whereas PGF2 $\alpha$ has no effect on anestrus cattle. AI technicians lack the experience and skills to effectively diagnose cyclicity of animals through palpation of the ovaries per rectum $[57,58]$, so non-cycling animals may have been included in the PGF $2 \alpha$ based breeding program. In this current study the on-farm progesterone assay confirmed the presence of CL, though our CIDR based estrus synchronization can be used at any stage of the estrous cycle, including in anestrus animals and prepubertal heifers.

Although farmers were advised to record animals in estrus, all animals were inseminated or naturally mated at a fixed time. This did not affect pregnancy regardless of pretreatment reproductive status of animals, breeding method, farming system or parity. This was similar to a previous report in cows and heifers, although they reported comparatively lower overall pregnancy rate than the present findings [13]. Some farmers in the study area prefer to have their own bull to using AI services due to numbers of reasons discussed in our recent reports $[6,58]$. Conception rate did not vary between breeding methods (AI vs bull) in the present study, yet a higher conception rate was found in animals bred with natural mating/bull than with AI, which could be due improper insemination. We recently evaluated the quality of frozen semen (sperm motility and viability) in the study area, and it was within the normal range [58]. In the present study, double inseminations at 48 and 72 hrs has resulted in improved pregnancy rate in all animal groups (anestrus, repeat-breeding and silent/unobserved estrus), in contrast to a previous report indicating the use of double insemination did not bring any significant difference in pregnancy rates compared to single insemination in repeatbreeder dairy cattle in other treatment regime [59]; it has also been proposed that double insemination can improve pregnancy by $5-10 \%$ [35].

Application of a progesterone (CIDR) based estrus synchronization programme is highly recommended to enhance fertility of dairy cattle. Furthermore, the expense of hormones required for estrus synchronization (US \$18.60/per animal: CIDR, US \$11.16 + PGF2 $\alpha$, US \$4.03 + eCG, US $\$ 3.41$ /animal) used in this study is less than the cost farmers spend feeding anestrus and repeat-breeder cows, with an estimated loss of production cost of US $\$ 148.48$ per cycle from single cow [29] for extended periods of time. This excludes the labour costs. In anestrus cattle, the cost of this estrus synchronization protocol can be further reduced to US $\$ 14.57$, as PGF2 $\alpha$ is not necessary in the absence of CL. Additionally, the prospect of reusing a used CIDR device [60] makes the protocol worthwhile.

\section{Conclusion}

The present study has shown a high estrus response, conception rate and calving rate in cows and heifers assigned to progesterone (CIDR) - PGF2 $\alpha$ - eCG based estrus synchronization protocol irrespective of pre-treatment reproductive condition, farming system and breeding methods. This study also confirms the effectiveness and affordability of the protocol. Thus, the protocol is recommended to enhance fertility of dairy cattle in the study area and other part of the country and improve the livelihood of the farming community. 


\section{Acknowledgments}

The authors would like to thank MRC Centre for Reproductive Health, College of Medicine and Veterinary Medicine, University of Edinburgh, United Kingdom for supporting ABM and funding the study. Special thanks are also offered to the College of Veterinary Medicine, Mekelle University, Ethiopia for the offer of transportation facilities and other support. Authors would like to thank Tigray Regional State Agriculture Bureau for facilitating the support team. Finally, the authors would like to express their deepest gratitude to the farmers, AI technicians and veterinarians for their willingness and co-operation during the study.

\section{References}

[1] Kumar, N. and Tkui, K. (2014). Reproductive performance of crossbred dairy cows in Mekelle, Ethiopia. Sci. J. Anim. Sci. 3(2): 35-40.

[2] Kumar, N., Abadi, Y., Gebrekidan, B. and Woldearegay, Y. H. (2014). Productive and Reproductive Performance of Local Cows under Farmer's Management in and around Mekelle, Ethiopia. IOSR-JAVS 7(5): 21-24.

[3] Dickson, N., Siew N., Singh-Knights, D., Bourne G. and Knights, M. (2012). Technical and Economic Outcome Using Various Timed Artificial Insemination Protocols in Dairy Cattle in the Tropics. J. Anim. Prod. Adv. 2(1): 490-499.

[4] Perez-Marin, C., Moreno, M. and Calero, G. (2012). Clinical approach to the repeat breeder cow syndrome. (Ed. PerezMarin C). A Bird's-Eye View of Veterinary Medicine, 337-362.

[5] Dubuc, J. (2011). Postpartum Uterine Diseases: Prevalence, Impacts, and Treatments. WCDS Advances in Dairy Technology. 23: 255-267.

[6] Mekonnin, A. B., Harlow, C. R., Gidey, G., Tadesse, D., Desta, G., Gugssa, T. and Riley, S. C. (2015a). Assessment of Reproductive Performance and Problems in Crossbred (Holstein Friesian X Zebu) Dairy Cattle in and around Mekelle, Tigray, Ethiopia. J. Anim. Vet. 3(3): 94-101.

[7] Shiferaw, Y., Tenhagen, B. A., Bekana, M. and Kassa. T. (2003). Reproductive performance of crossbredd cows in different production systems in the central highlands of Ethiopia. Trop. Anim. Health and Prod. 35: 551-561.

[8] Duguma, B., Kechero, Y. and Janssens, G-P. J. (2012) Productive and Reproductive Performance of Zebu X Holstein-Friesian Crossbred Dairy Cows in Jimma Town, Oromia, Ethiopia. Global Veterinaria 8(1): 67-72.

[9] Walker, W. L., Nebel, R. L. and McGillard, M. L. (1996). Time of ovulation relative to mounting activity in dairy cattle. J. Dairy Sci. 79: 1555-1561.

[10] Hansar, E., Lemma, A. and Yilma, T. (2014). Pre-service ultrasonic and manual evaluation of the reproductive organs of dairy cows presumed to be in estrus. Springer Plus 3: 529.

[11] Nebel, R. and DeJarnette, M. (2015). Dairy cow synchronization protocols. Select Sirs. Available at: http://www.selectsires.com/resources/fertilitydocs/dairy_cow synch_protocols.pdf. (Accessed 20 September 2015).
[12] Larson, J. E., Lamb, G. C., Stevenson, J. S., Johnson, S. K., Day, M. L., Geary, T. W., Kesler, D. J., DeJarnette, J. M., Schrick, F. N., DiCostanzo, A. and Arseneau, J. D. (2006). Synchronization of estrus in suckled beef cows for detected estrus and artificial insemination and timed artificial insemination using gonadotropin-releasing hormone, prostaglandin F, and progesterone. J. Anim. Sci. 84: $332-342$.

[13] Lamb, G. C, Dahlen, C. R., Larson, J. E., Marquezini, G. and Stevenson, J. S. (2010). Control of the estrous cycle to improve fertility for fixed-time artificial insemination in beef cattle: a review. J. Anim. Sci. 88(13 Suppl): E181-192.

[14] Patterson, D. J. Mallory, D. A. Nash, J. M. Martin, N. T. and Smith, M. F. (2011). Strategies to optimize use of AI in cow/calf production systems: focus on fixed-time AI protocols for cows Proceedings, Applied Reproductive Strategies in Beef Cattle - Northwest, September 30 - October 1, 2011; Boise, ID, USA.

[15] Williams, G., Stanko, R., Allen, C., Cardoso, R., Prezotto, L., Thorson, J., and Amstalden. M. (2011). Evidence that prostaglandin administration at the onset of a 5-day CO-Synch + CIDR synchronization protocol markedly improves fixedtime AI pregnancy rates in Bos indicus-influenced cattle. $J$. Anim. Sci. 89 (E-Suppl. 1): 264.

[16] Siregar, T. N., Hamdan, H., Riady, G., Panjaitan, B., Aliza, D., Pratiwi, E. F., Darianto T., and Husnurrizal (2015). Efficacy of Two Estrus Synchronization Methods in Indonesian Aceh Cattle. Inter. J. Vet. Sci. 4(2): 87-91.

[17] DeJarnette, M. (2015). Ovsynch, Co-synch, Presynch and Kitchensynch: how did breeding cows get so complicated? Select Sires. pp. 1-6. Available at: http://www.selectsires.com (Accessed 2 September 2015).

[18] Yelich, J. V. and Bridges, G. A. (2012). Synchronization response: Bos taurus vs. Bos indicus cattle. A review. Beef Improvement Federation (BIF) Research Symposium and Annual Meeting, April 18-21, 2012, Houston, Texas, USA.

[19] Powell, J. G., Lester, T. D., Reynolds, J. L., Davis, A. J., Hornsby, J. A. and Rorie, R. W. (2012). Comparison of a 5- or 14-day CIDR-based estrous synchronization protocols with sorted semen in beef heifers. AAES Research Series 606. pp. 51-53.

[20] Maurer, R. E., Webel, S. K. and Brown, M. D. (1975). Ovulation control in cattle with progesterone intravaginal device (PRID) and gonadotropin releasing hormone (GnRH). Ann. Biol. Anim. Bioch. Biophys. 15: 291-296.

[21] Macmillan, K. L. and Peterson, A. J., (1993). A new intravaginal progesterone releasing device for cattle (CIDR-B) for oestrous synchronization, increasing pregnancy rates and the treatment of postpartum anoestrus. Anim. Reprod. Sci. 33: $1-25$.

[22] Gordon, I. (1999). Artificial control of oestrus and ovulation. In: I. Gordon (ed.) Controlled reproduction in cattle \& buffaloes. CAB Int. Publ., Wallingford, UK, pp. 133-166.

[23] Palomares, R. A., Fishman, H. J., Jones, A. L., Ferrer, M. S., Jenerette, M. and Vaughn A. (2015). Comparison of 4- versus 5-day Co-Synch $\mathrm{p}$ controlled internal drug release (CIDR) $\mathrm{p}$ timed artificial insemination protocols in dairy heifers. Theriogenology 84: 868-874. 
[24] Bridges, G. A., Helser, L. A., Grum, D. E., Mussard, M. L., Gasser, C. L. and Day, M. L. (2008). Decreasing the interval between GnRH and PGF2alpha from 7 to 5 days and lengthening proestrus increases timed-AI pregnancy rates in beef cows. Theriogenology 15: 843-851.

[25] Broadbent, P. J., Tregaskes, L. D., Dolman, D. F., Franklin, M. F. and Jones, R. L. (1993). Synchronlzatlon of estrus in embryo transfer recipients after using a combination of PRID or CIDR-B plus PGF2 $\alpha$. Theriogenology 39: 1055-1065.

[26] Kim, U. H., Suh, G. H., Hur, T. Y., Kang, S. J., Kang, H. G., Park, S. B., Kim, S. H. and Kim, I. H. (2007). Comparison of two types of CIDR-based timed artificial insemination protocols for repeat breeder dairy cows. J. Reprod. And Develop. 53: 639-645.

[27] Bridges, G. A., Lake, S. L., Kruse, S. G., Bird, S. L., Funnell, B. J., Aries, R., Walker, J. A., Grant, J. K. and Perry, G. A. (2014). Comparison of three CIDR-based fixedtime AI protocols in beef heifers. J. Anim. Sci. 92: $3127-$ 3133 .

[28] Romano, J. E. and Fahning, M. L. (2013). Comparison between 7 vs 9 days of controlled internal drug release inserts permanency on oestrus performance and fertility in lactating dairy cattle. Ital. J. Anim. Sci. 12(e63): 390-394.

[29] Hailu, B., Gebrekidan, B., Raju, S., Birhanu, A. and Tadesse, G. (2015). Effects of Gonadotropin Releasing Hormone Analogue in Enhancements of Pregnancy in Repeat Breeding Dairy Cows in and around Mekelle, Tigray, Ethiopia. Anim. Vet. Sci. 3(1): 12-17.

[30] Mekonnin, A. B. Harlow, C., Howie, F., Gidey, G., Tadesse, D., Desta, G., Ashebir, G., Gebrekidan, B., Gugsa, T. and Riley, S. C. (2015b). Assessment of major reproductive problems and reproductive status of crossbred (Holstein Friesian X Zebu) dairy cattle in and around Mekelle, Tigray, Ethiopia. Society for Reproduction and Fertility annual conference, 19-22 July 2015, Oxford, UK.

[31] BoPED (2011). Bureau of Planning and Economic Development: Tigray, Ethiopia.

[32] DEFRA (2001). Condition scoring of dairy cows: Action on animal health and welfare. The Department for Environment, Food and Rural Affairs, UK.

[33] Kawate, N., Watanabe, K., Urnaka, K., Takahashi, M., Inaba, T. and Tamada, H. (2011). Comparison of plasma concentration of estradiol $17 \beta$ and progesterone, and conception in dairy cows with cystic ovarian diseases between Ovsynch and Ovsynch plus CIDR timed protocols. J. Reprod. Develop. 57: 267-272.

[34] Lucy, M. C., Billings, H. J. Butler, W. R. Ehnes, L. R. Fields, M. J. Kesler, D. J. Kinder, J. E. Mattos, R. C. Short, R. E. Thatcher, W. W. Wettemann, R. P. Yelich, J. V. and Hafs. H. D. (2001). Efficacy of an Intravaginal Progesterone Insert and an Injection of PGF2a Synchronizing Estrus and Shortening the Interval to Pregnancy in Postpartum Beef cows, Peripubertal Beef Heifers, and Dairy Heifers. J. Anim. Sci. 79: 982-995.

[35] EBLEX, (2014). Artificial insemination (AI) and oestrus synchronisation of beef cattle. Better Returns Program (BRP). pp. 1-12. http://beefandlamb.ahdb.org.uk/wp/wpcontent/uploads/2014/07/BRP-plus-artificialinsemination090714.pdf. (Accessed 12 September 2015).
[36] Racowsky, C. (1991). Gamete resources: origin and production of oocytes. (Eds. Pedersen RA., McLaren A, First, NL). Animal applications of research in mammalian development. Current communications in cell and molecular biology 4, 26-38, Cold Spring Harbor Laboratory Press, New York, USA.

[37] Gospodarowicz, D. (1972). Purification and physiochemical properties of pregnant mare serum gonadotropin (PMSG). Endocrinology 91: 101-106.

[38] Sá Filho, O. G, Meneghetti, M., Peres, R. F., Lamb, G. C. and Vasconcelos, J. L. (2009). Fixed-time artificial insemination with estradiol and progesterone for Bos indicus cows II: strategies and factors affecting fertility. Theriogenology 72 : 210-218.

[39] Tegegne, A., Franceschini, R. and Sovani, S. (1994). Superovulatory response, embryo recovery and progesterone secretion in Boran (Full-size image $(<1 \mathrm{~K})$ ) cows after treatment with either Pergovet or Pluset. Theriogenology 41(8): 1653-1662.

[40] Grant, E. (2006). Understanding CIDR. National Association of Animal Breeders. Accessed at: $\mathrm{http} / / /$ beefmagazine.com/mag/beef_understanding_cidr (Accessed 10 September 2015).

[41] Garcia-Winder, M., Lewis, P. E., Deaver, D. R., Smith, V. G., Lewis, G. S. and Inskeep, E. K. (1986). Endocrine profiles associated with life span of induced corpora lutea in postpartum beef cows. J. Anim. Sci. 62: 1353-1362.

[42] Rosenberg, M., Kaim, M., Herz, Z. and Folman, Y. (1990). Comparisons of methods for synchronization of estrous cycle in dairy cows. 1. Effects on plasma progesterone and manifestation of estrus. J. Dairy Sci. 73(10): 2807-2816.

[43] Fike, K. E., Day, M. L, Inskeep, E. K., Kinder, J. E., Lewis, P. E., Short, R. E. and Hafs, H. D. (1997). Estrus and luteal function in suckled beef cows that were anestrous when treated with an intravaginal device containing progesterone with or without a subsequent injection of estradiol benzoate. $J$. Anim. Sci. 75(8): 2009-2015.

[44] McDougall, S., Burke, C. R., Macmillan, K. L. and Williamson, N. B. (1992). The effect of pretreatment with progesterone on the oestrous response to oestradiol-17 $\beta$ benzoate in the post-partum dairy cow. Proc. N.Z. Soc. Anim. Prod. 52: 157-160.

[45] Gasser, C. L. (2013). Joint Alphapharma - Beef Species Symposium, considerations on puberty in replacement beef heifers. J. Anim. Sci. 91: 1336-1340.

[46] McNally, J. C., Crowe, M. A., Roche, J. F., Beltman, M. E. (2014). Effects of physiological and/or disease status on the response of postpartum dairy cows to synchronization of estrus using an intravaginal progesterone device. Theriogenology 82(9): 1263-1272.

[47] Singh, H., Luthra, R. A., Khar, S. K. and Nanda, T. (2006). Oestrus Induction, Plasma Steroid Hormone Profiles and Fertility Response after CIDR and eCG Treatment in Acyclic Sahiwal Cows. Asian-Aust. J. Anim. Sci. 19(11): 1566-1573.

[48] Virmani, M., Malik, R. K., Dalal, D. S., Singh, P. and Vikash (2013). Comparing efficacy of different hormonal protocols for induction of cyclicity in postpartum anestrus Sahiwal cows. Haryana Veterinarian 52: 121-123. 
[49] Kasimanickam, R., Schroeder, S., Hall, J. B. and Whittier, W. D. (2015). Fertility after implementation of long- and shortterm progesterone-based ovulation synchronization protocols for fixed-time artificial insemination in beef heifers. Theriogenology 83: 1226-1232.

[50] Gordon, I. (1996). Controlled reproduction in cattle and buffaloes. CAB International. Wallingford, UK.

[51] Lamb, G. C., Stevenson, J. S. Kesler, D. J. Garverick, H. A. Brown, D. R. and Salfen, B. E. (2001). Inclusion of an intravaginal progesterone insert plus $\mathrm{GnRH}$ and prostaglandin $\mathrm{F} 2 \alpha$ for ovulation control in postpartum suckled beef cows. $J$. Anim. Sci. 79: 2253-2259.

[52] Colazo M. G., Kastelic, J. P, Whittaker, P. R., Gavaga, Q. A., Wilde, R., Mapletoft, R. J. (2004). Fertility in beef cattle given a new or previously used CIDR insert and estradiol, with or without progesterone. Anim. Reprod. Sci. 81: 25-34.

[53] Smith, M. W. and Stevenson. J. S. (1995). Fate of the dominant follicle, embryonal survival, and pregnancy rates in dairy cattle treated with prostaglandin F2 $\alpha$ and progestins in the absence or presence of a functional corpus luteum. $J$. Anim. Sci. 73: 3743-3751.

[54] Zobel, R., Rkalcic, S., Pipal, I. and Buic, V. (2011). Incidence and factors associated with early pregnancy losses in Simmental dairy cows. Anim. Reprod. Sci. 127: 121-125.

[55] Mekonnin, A. B, Tadesse, G., Bitsue, H. K. and Khar, S. K.
(2016). Efficacy of a Modified GnRH-PGF Combination for 2 Estrous Synchronization in Dairy Cattle. Global Veterinaria 16(2): 200-205.

[56] Giday, J. (2014). Livestock development in Tigray, an overview of past and current development efforts. Livestock Development and Animal Health Services Main Department, Tigray BoARD, Mekelle, Tigray, Ethiopia. A report presented at International Conference on Enhancing Economic Growth and Public Health through Livestock Development and One Health Approach (Mekelle, Ethiopia)

[57] Lobago, F. (2007). Reproductive and lactation performance of dairy cattle in the Oromia Central Highlands of Ethiopia with special emphasis on pregnancy period. Doctoral thesis Swedish University of Agricultural Sciences, Uppsala.

[58] Ashebir, G., Birhanu A. and Gugsa, T. (2016). Status of artificial insemination in Tigray Regional State, "Constraints and acceptability under field condition". J. Dairy Vet. Anim. Res. 3(3): 00078. DOI: 10.15406/jdvar.2016.03.00078.

[59] Stevenson, J. S., Call, E. P. Scoby, R. K. and Phatak, A. P. (1990). Double insemination and gonadotropin releasing hormone treatment of repeat-breeding dairy cattle. J. Dairy Sci. 73: 1766.

[60] Abdallah, H. and Abd El Rahim, A. (2014). Efficiency of previously used CIDR stored for a prolonged period. $A d v$. Anim. Vet. Sci. 2(9): 508-515. 